\title{
16S microbial phylogeny of multifunctional plant-growth-promoting rhizobacteria from the rhizosphere of maize (Zea mays L.) for agricultural soil fortification
}

\author{
REena JosePhine, JiBU THOMAS* \\ Karunya Institute of Technology and Sciences, Department of Biosciences and Technology, Coimbatore, India
}

\begin{abstract}
Soil microbial diversity plays an important role among the factors that affect plant growth. The present study was conducted with a focus on the isolation and characterization of native microbial strains from maize rhizosphere and the determination of their abilities for promoting plant growth and biocontrol in the for the fortification of agricultural soil. We isolated 156 microbial strains and qualitatively assayed their ability to synthesize ammonia, phosphate, indole acetic acid (IAA), and siderophores. Moreover, we tested their biocontrol traits, such as the synthesis of hydrolytic enzymes and antagonistic potential toward the fungal pathogen Fusarium moniliforme. Of the strains tested, 106 produced ammonia, 55 solubilized phosphate, 71 synthesized indole-3-acetic acid (IAA), 33 were positive for siderophores, 83 were able to hydrolyze cellulose, 84 were pectinase producers, and 44 strains were antagonistic to Fusarium moniliforme, a pathogen of maize. The potential strains were selected and phylogenetically characterized using $16 \mathrm{~S}$ rRNA sequencing to study their evolutionary relatedness. Phylogenetic studies have revealed organisms of the genera Bacillus, Pseudomonas, Klebsiella, and Acinetobacter, which were previously found to be associated with the rhizosphere of maize and have varied diversity at the species level. The retrieved sequences were then submitted to the GenBank database. We found that a majority of the tested strains possessed at least one or more plant-growth-promoting features, indicating their role as potential plant-growthpromoting rhizobacteria (PGPRs). An application of these microorganisms in the field as PGPRs or biocontrol agents should be beneficial for sustainable agriculture.
\end{abstract}

Key words: Fusarium, IAA, maize, PGPR, 16S rRNA sequencing

\section{Introduction}

The global population has reached 7 billion, and it is estimated that it could reach 11 billion (average estimate of $70 \%$ increase in the population) by the year 2100 (EEA, 2015), which would necessitate an enhanced demand for food. This unprecedented increase in the world population could result in a social threat to food security. Agricultural practices to feed the increasing population are a very important task of the $21^{\text {st }}$ century (Glick, 2014). Therefore, it is mandatory to improve agricultural productivity over the next few years.

Unfortunately, we currently observe a rapid decline in agricultural productivity due to unfavorable environmental conditions that may hamper plant growth. These negative physical and environmental factors include a change in soil $\mathrm{pH}$, salinity, temperature, and drought. Similarly, biological factors include pest infestation and phytopathogen-induced diseases that induce a decline in crop productivity (Ladeiro, 2012).The problems associated with these pests and pathogens are partially overcome bythe application of chemicals to the agroecosystem to improve crop productivity. However, the continuous use of chemical agents has adverse effects on the environment and poses severe environmental and health hazards, besides being expensive.

Given the disadvantages of chemical use in agriculture, it is necessary to provide long-term, sustainable, and eco-friendly solutions to the world food problem.

\footnotetext{
* Corresponding author: Karunya Institute of Technology and Sciences, Department of Biosciences and Technology, Coimbatore, India; e-mail: jibuthomas.t@gmail.com
} 
In this context, the persistent use of plant-growth-promoting rhizobacteria (PGPR) in agriculture is an attractive alternative. PGPRs are diverse groups of bacteria that colonize the rhizosphere regions and enhance plant growth through a multifaceted approach. Therefore, they are an inherent part of the ecological niche of the rhizosphere biota involved in plant growth and biocontrol (Bashan and Levanomy, 1990). In view of the beneficial activities rendered by PGPR toward plant growth and environmental sustainability, it is essential to consider harnessing the efficacy of these strains in agriculture. With better understanding of their mechanisms of growth promotion, these microbial strains can be applied as efficient inoculants for agriculture.

Maize is the most extensively grown cereal that provides the requisite carbohydrates to billions of individuals; it accounts for nearly 850 million metric tons of global annual crop production per year (Peiffer and Ley, 2013). In India, maize is the third most cultivated grain, after rice and wheat, and comprises $\sim 9 \%$ of the total volume of cereal production. Due to simple farming practices and continuously increasing demand for maize in India, it is being cultivated two to three times a year; this is achieved through the application of large amounts of nitrogenous fertilizers, which results in the deterioration of soil health and the environment (Joshi et al., 2006). Thus, the use of PGPRs to replaceagrochemicals has recently received considerable attention in the promotion of plant growth, which occurs by various mechanisms that involve formation of soil structure, recycling of essential nutrients, production of numerous plant growth regulators, increasing of soil fertility, and combating of different plant pathogens, thereby promoting changes in vegetation (Sivasakthi et al., 2014). Inoculation of PGPRs in cereal plants by using bacterial genera such as Azospirillum, Bacillus, Klebsiella, Herbaspirillum, BurkholderiaI, and Pseudomonas spp.(associated with cereals, including maize, and other crops) has been found to increase crop yields (Wu et al., 2005; Mehnaz et al., 2010). In this regard, commercially available diverse PGPRs - in combination or as individual strains are used as formulations in crops (Swarnalakshmi et al., 2013).Therefore, it is necessary to isolate region-specific native microbial strains that can be used as potential plant-growth promoters. Knowledge of indigenous bacterial populations is required to analyze region-specific microbes, as they can easily acclimatize to the existing environmental conditions and exhibit enhanced plantgrowth-promoting (PGP) activities. However, strains that perform well under laboratory conditions may not do so in the field. Therefore, the present study was conducted to 1 ) isolate native microbial strains associated with the maize rhizosphere from different maize-growing regions in and around Coimbatore, India; 2) to screen the isolated strains in vitro for PGP abilities and biocontrol traits; 3 ) to verify the antagonistic activity of the strains against the maize pathogen Fusarium moniliforme; and 4) identification of the isolated strains through 16S rRNA sequencing to evaluate the diversity of microbial populations. Molecular approaches based on $16 \mathrm{~S}$ rRNA gene sequencing are rapid and easy techniques for identifying soil isolates, as compared to conventional biochemical approaches.

\section{Materials and methods}

\section{Isolation and screening of microbial strains}

The soil from three different maize fields in the Coimbatore region (latitude: $11^{\circ} 14^{\prime} 60.00^{\prime \prime} \mathrm{N}$ longitude: $77^{\circ} 18^{\prime} 60.00^{\prime \prime} \mathrm{E}$ ) of Tamil Nadu, India, was used for this study. Rhizosphere samples were collected (21 BBCH stage of the maize crop) and processed according to standard microbiological procedures of serial dilution and the spread-plate method. Individual strains were chosen based on colony morphology, and pure cultures were maintained as $60 \%$ glycerol stocks stored at $-20^{\circ} \mathrm{C}$. Strains were denoted by the field, field number, and strain number. We included 31 strains from Field 1 (F1), 21 from Field 2 (F2), and 104 from Field 3 (F3) based on culture characteristics, namely, the color of the colony, appearance, and pigmentation, and they were subsequently used in this study. These maize fields were selected because they were the predominant maize cultivation regions.

\section{In vitro plant-growth-promotion traits}

The strains were screened for their ability to synthesize different compounds such asammonia, IAA, and siderophores.

\section{Production of ammonia, siderophores, IAA, and phosphate solubilization}

Test bacterial strains were inoculated in peptone water, which contained peptone as the nitrogen source, and they were incubated for $48-72 \mathrm{~h}$ at $28^{\circ} \mathrm{C}$. Yellow to 
brownish coloration within the tubes after the addition of Nessler's reagent $(0.5 \mathrm{~mL})$ indicated a positive result for the presence of ammonia (Cappuccino and Sherman, 1992). The production of siderophores was detected using Chrome azurol S agar medium, as described by Schwyn and Neilands (1987), and the mixture was incubated at $37^{\circ} \mathrm{C}$ for $48-72 \mathrm{~h}$. The development of a yellow halo around the colonies indicated the production of siderophores. Strains were inoculated onto the modified Pikovaskya medium (containing $0.4 \%$ bromophenol blue dye) and incubated at $37^{\circ} \mathrm{C}$ for $72 \mathrm{~h}$. The appearance of yellowish halo zones around the colonies indicated the hydrolysis of phosphates (Gupta et al., 1994). Bacterial cultures were grown in Luria Bertani broth amended with $100 \mathrm{mg}$ L-tryptophan $\mathrm{l}^{-1}$ with constant agitation (150 rpm) at $28 \pm 2{ }^{\circ} \mathrm{C}$ for $48 \mathrm{~h}$; afterward, these cultures were centrifuged at $1008 \mathrm{~g}$ for $30 \mathrm{~min}$. A change in color of the culture supernatant to pink after the addition of Salkowski's reagent $(50 \mathrm{ml}, 35 \%$ perchloric acid, $1 \mathrm{ml} 0.5 \mathrm{M} \mathrm{FeCl}_{3}$ solution) to the culture supernatant indicated the presence of IAA (Bric et al., 1991).

\section{In vitro plant-growth-biocontrol traits}

Plant growth promotion can be achieved indirectly through the biocontrol activity ofmicrobial strains against plant pathogens, with possible mechanisms for these including the production of antibiotics, toxins, and surface active compounds, or that of extracellular cellwall-degrading enzymes such as chitinase and $\beta$-1, 3-glucanase (Whipps, 2001).

Analyses of protease, cellulase, pectinase, amylase, and chitinase activities

The protease activity of the tested strainswas determined by using skim milk agar inoculated with the test bacterial strains. A zone of hydrolysis around the colonies after the incubation period indicated a positive result (Cappucino and Sherman, 1992). We prepared an M9 medium with $10 \mathrm{~g} \cdot 1^{-1}$ cellulose and $1.2 \mathrm{~g} \cdot \mathrm{l}^{-1}$ yeast extract for the hydrolysis of cellulose; this medium was inoculated with the test strains and incubated at $37^{\circ} \mathrm{C}$ for $48 \mathrm{~h}$. An aqueous solution of Gram's iodine was poured onto the agar surface to observe the hydrolysis zones. Gram's iodine formed a bluish-black complex with cellulose within 3-5 min, but not with the hydrolyzed cellulose, which indicated a positive result (Kasana et al.,
2008). Pectinase activity was detected by plating the bacterial cultures onto M9 medium with $4.8 \mathrm{~g} \cdot 1^{-1}$ pectin and $1.2 \mathrm{~g} \cdot 1^{-1}$ yeast extract and incubation at $37^{\circ} \mathrm{C}$ for $72 \mathrm{~h}$. A zone of hydrolysis was evident after the addition of Gram's iodine solution to the culture plates, which indicated a positive result (Cattelan et al., 1999). To detect the production of amylase, the test bacterial strains were incubated in starch agar plates and then flooded with Lugol's iodine solution (Das et al., 2004). Amylase activity was indicated by halo zones that did not turn blue on addition of iodine solution due to the utilization of starch by the bacterial strains. To detect the chitinase activity, colloidal chitin was prepared from chitin by the method proposed by Hsu and Lockwood (1975). Chitin agar was prepared by using the M9 medium with $2 \%$ chitin and inoculated with the test strains. A zone of hydrolysis around the colonies indicated a positive result.

\section{Antifungal activity against Fusarium moniliforme}

Antagonism studies were conducted in vitrowith the tested bacterial strains against Fusarium moniliforme (MTCC Strain No. 2088) that causes ear rot and stalk rot in maize. A dual-culture technique (Lahlali et al., 2007) was used with the test bacterial strain on one side and the fungus on the other side of the agar plate. Plates with only the test pathogen served as controls. We observed radial mycelial growth and zones of inhibition were compared with those on the control plates.

\section{SrDNA sequencing and phylogeny}

Bacterial strains with multiple PGP activities were identified using $16 \mathrm{~S}$ rDNA sequencing. The alkaline lysis method was used to isolate the genomic DNA from the test bacterial strains (Sambrook et al., 1989). The $16 \mathrm{~S}$ rRNA gene in the genomic DNA was targeted using primers (F) 5'AGTTTGATCCTGGCTCAG3' and (R) 5'AC GGCTACCTTGTTACGACTT3' (CDFD, Hyderabad, India). Amplification reactions contained $50 \mathrm{ng}$ genomic DNA, $1 \times$ Taq DNA polymerase buffer, 1 U Taq DNA polymerase, $1.5 \mathrm{mM} \mathrm{MgCl}_{2}, 0.2 \mathrm{mM}$ of each dNTP, and $10 \mathrm{pM}$ of each primer. PCR was conducted in a VertiThermo cycler (Applied Biosystems) at $95^{\circ} \mathrm{C}$ for $5 \mathrm{~min}$, followed by 30 cycles of $1 \mathrm{~min}$ at $95^{\circ} \mathrm{C}, 1 \mathrm{~min}$ at $50^{\circ} \mathrm{C}$, and 2 min at $72^{\circ} \mathrm{C}$, with an extension of $72^{\circ} \mathrm{C}$ for $10 \mathrm{~min}$. The amplicons were visualized in $1.4 \%$ agarose gel under a UV transilluminator. 
Purified PCR fragments were directly sequenced with a ABI PRISM Big Dye terminator cycle sequencing ready reaction kit on an ABI Prism3100 Genetic Analyser. The chromatograms thus obtained were edited using FINCH TV 1.4. These sequences were phylogenetically compared with those of all the species from closely related genera, which were retrieved from the NCBI GenBank BLAST program (Altschul et al., 1997). The phylogenetic tree was constructed by the neighborjoining method, with the Methanothermococcus thermolithotrophicus strain DSM 2095 as the out group (Saitou and Nei, 1987), using MEGA version 6.06 software (Tamura et al., 2011). Tree topologies were evaluated by conducting bootstrap analyses using 1,000 re-samplings. Thepartial sequences of $16 \mathrm{~S}$ rRNAwere matched against sequences present in GenBank by using the BLASTn program, and then deposited in the GenBank database for the accession numbers.

\section{Results}

\section{Isolation of rhizospheric bacteria}

Based on the culture characteristics, we selected 156 microbial strains from different culture plates and they were evaluated by different assays throughout the study.

\section{In vitro PGP traits}

Production of ammonia, phosphate, IAA, and siderophores

Rhizobacteria improve the nutrient status of plants by fixing atmospheric nitrogen in the form of nitrate or ammonia, solubilizing phosphorous, secreting siderophores that are iron chelators to supply iron to plants or to make the $\mathrm{Fe}$ unavailable to the pathogens, and by secreting plant hormones such asindole-3-acetic acid to act as phytostimulators. Of the 156 strains tested, 87 (56\%) developed a yellow color on addition of Nessler's reagent, thereby indicating the potential for the production of ammonia; however, 31 strains $(24 \%)$ showed moderate production of ammonia. Further, 37 strains (24\%) developed a high zone of hydrolysis in Pikovskaya's agar, which indicates phosphate-solubilization abilities, and 18 strains (11\%) showed a moderate hydrolysis of phosphates (Fig. 1). Moreover, 32 strains (21\%) exhibited a strong production of the PGP hormone IAA, whereas $39(25 \%)$ showed a moderate color change indicating IAA production. Nineteen strains (13\%) produced siderophores and, of these, 14 (10\%) were mo-



Fig. 1. Percentage of strains exhibiting PGP traits to the total number of strains that were studied

derate siderophore producers (Fig. 1). Among the strains, isolates from Field 3 (36 strains) showed a good production of IAA compared to strains from other fields. Test strains from fields 2 and 3 (50 strains) gave a positive result for phosphate solubilization, compared to strains from Field 1 . The majority of the strains from Field 2 (15 strains) showed a positive result for siderophores.

\section{In vitro plant-growth biocontrol traits}

\section{Cell-wall-degrading enzymes}

Of the 156 strains tested, 46 (29\%) produced clear zones around the colonies on skim milk agar and 26 (17\%) produced moderate zones of hydrolysis. Fifty strains (32\%) produced cellulose and, of these, 33 (21\%) exhibited moderate cellulose production. In addition, 42 strains each (27\%) hydrolyzed pectin andshowed narrow zones of hydrolysis. Seventy-three (47\%) strains exhibited amylase activity by producing distinct halo zones on starch agar; of these, 27 strains (17\%) exhibited moderate amylase productionand $44(28 \%)$ exhibited strong potential to hydrolyze chitin (Fig. 2). Compared to the strains from other fields, Field 3 strains (35 strains) showed good results, thus indicating their ability to hydrolyze most of the substrates tested by producing various extracellularly secreted enzymes. Out of 156 strains, 34 strains (22\%) developed well-defined zones of 


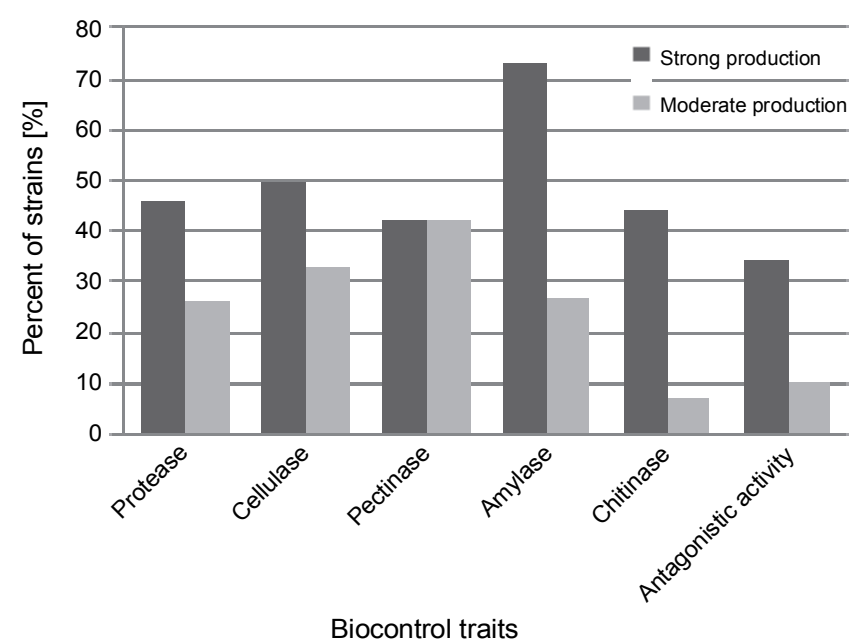

Fig. 2. Percentage of strains exhibiting biocontrol traits to the total number of strains that were studied

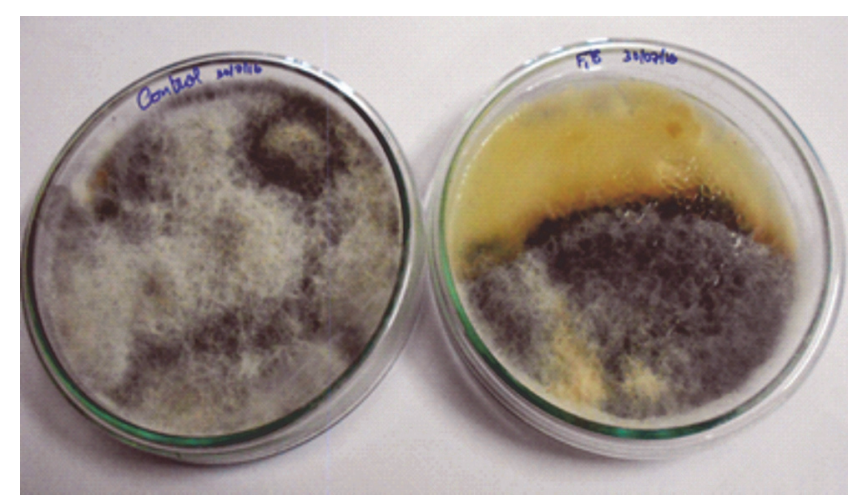

Fig. 3. Antifungal activity determined by dual-culture bioassay against Fusarium moniliforme

hydrolysis towards Fusarium moniliforme in vitro, with $10(6 \%)$ producing distinct zones of inhibition against the pathogen (Fig. 3). Most strains from Field 2 (17 strains) showed good antagonistic potential, compared to strains from other fields. The PGP and biocontrol traits of the selected strains are summarized in Table 1.

\section{Molecular phylogeny of bacterial strains}

In total, 48 strains were selectedon the basis of cultural characteristics, and PGP abilities were sequenced and affiliated to bacterial species by using BLASTn and phylogenetic tree analysis (Fig. 4). Based on 16S RNA phylogeny, the majority of the bacteria from the maize rhizosphere were divided into the Firmicutes and Gammaproteo bacteria classes. The selected isolates mainly belonged to the genera Bacillus, Pseudomonas, Klebsiella, Acinetobacter, Fictibacillus, Pantoea, and Leuco- bacter. The genera Bacillus showed high diversity with different species such as $B$. subtilis, $B$. nematocida, $B$. pseudomycoides, $B$. thuringiensis, $B$. amyloliquefaciens, $B$. firmus, $B$. oceanisedismus, $B$. flexus, B. licheniformis, $B$. anthracis, $B$. cereus, $B$. pumilus, $B$. atrophaeus, B. endophyticus, and B. sonorensis as well as Fictibacillus that resembled Bacillus. Similarly, the genera Pseudomonas exhibited diversity, with species such as $P$. aeruginosa, $P$. putida, $P$. montelli, and $P$. indoloxydans. The species Acinetobacter pitti, Klebsiella pneumoniae, and Leucobactertardus were represented by one isolate each. The sequences were deposited in the EMBL/ GenBank database under the accession numbers: KM657433 (F1 4), KM677193 (F2 3), KM677194 (F2 5), KP462863 (F3 7), KP462864 (F3 11), KP462865 (F3 12), KP462866 (F3 17), KP462867 (F3 18), KP462868 (F3 21), KP462869 (F3 26), KP462870 (F3 25), KP462871 (F3 43), KP462872 (F3 44), KP462873 (F3 45), KP462874 (F3 47), KP462875 (F3 53), KP462876 (F3 54) and KT735204 (F1 8), KT735205 (F1 5), KT735206 (F1 12), KT735207 (F1 15), KT735208 (F1 21), KT735209 (F2 10), KT735210 (F2 13), KT735211 (F2 14), KT735212 (F3 10), KT735213 (F3 1), KT735214 (F2 3), KT735215 (F3 6), KT735216 (F3 9), KT735217 (F3 19), KT735218 (F3 22), KT735219 (F3 46), KT735220 (F2 8),KT735221 (F2 15), KT735222 (F2 20), KT735224 (F3 20), KT735225 (F3 48), KT735226 (F3 49), KT735227 (F3 50), KT735228 (F3 51), KT735229 (F3 57), KT735230 (F3 28), KT735231 (F3 30), KT735232 (F3 32), KT735233 (F3 33), KT735234 (F3 34), KT735235 (F3 60), and KT735236 (F3 61). The similarity of the $16 \mathrm{~S}$ rRNA gene sequence of the strains and their similarity index with other validly published species is depicted in Table 2 .

The phylogenetic analysis inferred that the clads could be divided into five divisions. The first group consisted of bacteria belonging to the different genera of Bacillus, namely, F1 8, F1 12, F1 19, F1 21, F2 3, F3 6, F3 7, F3 9, F3 11, F3 12, F3 17, F3 18, F3 20, F3 21, F3 23, F3 25, F3 30, F3 32, F3 34, F3 48, F3 50, F3 51, and F3 61, which show $99 \%$ homology to the different species of Bacillus. The second group comprised different members of Pseudomonas, including isolates, namely, F2 12, F2 13, F2 14, F3 43, F3 44, F3 45, F3 47, and F3 54 ,that exhibited $99 \%$ similarity with the previously reported strains of Pseudomonas. The third, fourth, and fifth groups consisted of F3 53 which resembled Leuco- 
Table 1. Characterization of the isolated rhizobacteria for some metabolic activities in vitro

\begin{tabular}{|c|c|c|c|c|c|c|c|c|c|}
\hline $\begin{array}{l}\text { Bacterial } \\
\text { group }\end{array}$ & Ammonia & Phosphate & IAA & Siderophore & Protease & Amylase & $\begin{array}{l}\text { Antagonistic } \\
\text { studies }\end{array}$ & Cellulase & Pectinase \\
\hline \multirow{3}{*}{ Bacilli } & + & ++ & + & - & + & + & ++ & + & - \\
\hline & ++ & ++ & + & - & + & + & ++ & - & - \\
\hline & +++ & ++ & ++ & - & ++ & +++ & - & +++ & +++ \\
\hline \multirow{4}{*}{ Pseudomonads } & ++ & + & ++ & ++ & +++ & ++ & - & + & + \\
\hline & ++ & + & +++ & ++ & ++ & ++ & - & + & ++ \\
\hline & + & ++ & +++ & ++ & - & + & - & +++ & +++ \\
\hline & ++ & ++ & ++ & + & - & - & ++ & - & - \\
\hline
\end{tabular}

+++/++ - strong production; + - moderate production; - - no production; IAA - indole acetic acid

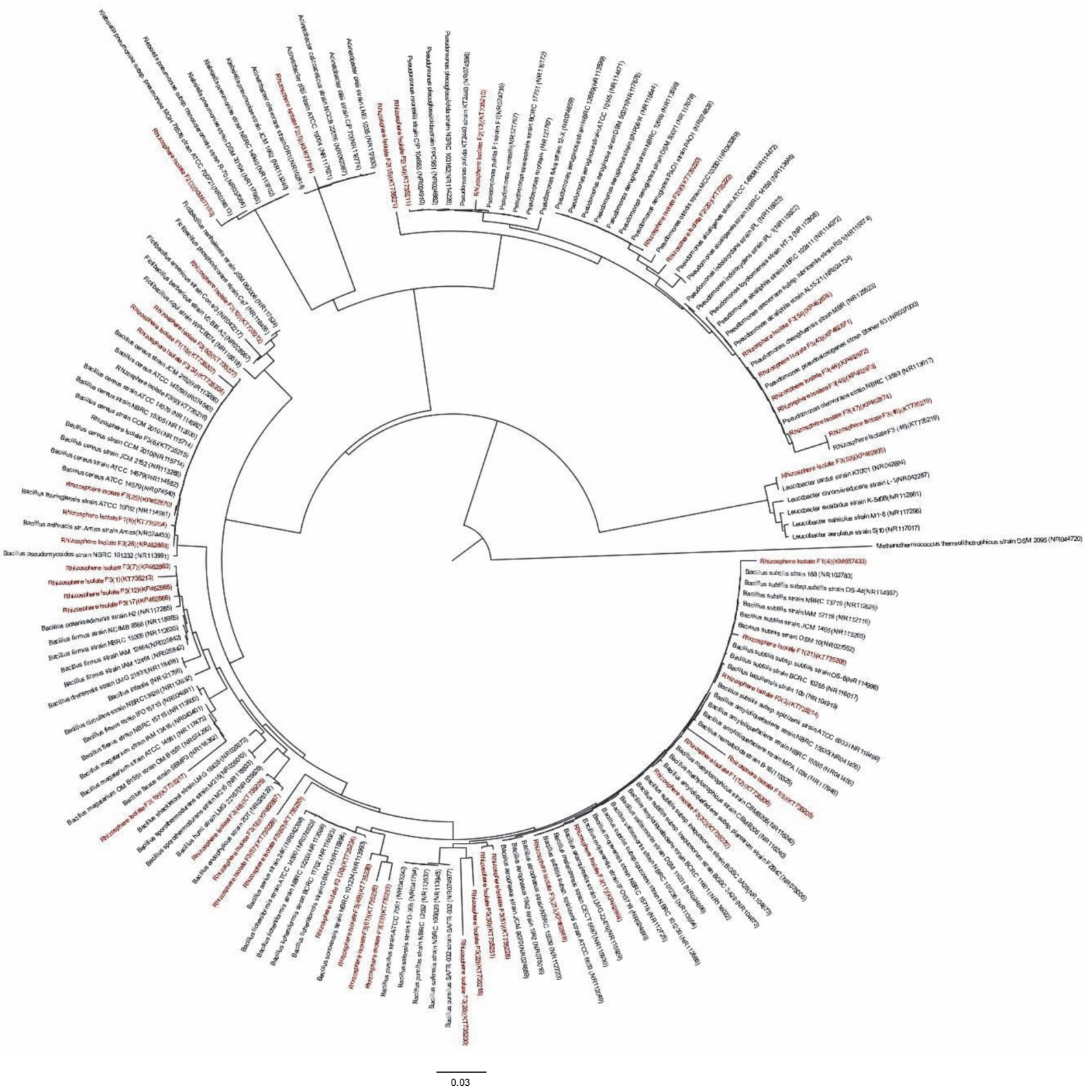

Fig. 4. 16S rRNA sequence-based phylogenetic tree showing relationships between the strains and representative bacteria of different genera 
bactertardus (99\%), F2 3 which resembled Klebsiella pneumoniae (97\%), and F2 5 which resembled Acinetobacterpittii (98\%). The isolates namely F1 4, F1 15, F3 1, F3 19, F3 22, F3 28, F3 33, F3 49, F3 57, F3 60 and F3 61 showed a sequence similarity of $97 \%$ or less. This low sequence similarity of the isolates paves the way for their further characterization for the identification of novel species through the use of other molecular tools such as whole genome sequencing and complete taxonomical analysis.

\section{Discussion}

The unsystematic application of chemical fertilizers and pesticides by agriculturalists has resulted in adverse side effects and, therefore, researchers are increasingly focusing their attention toward biological and ecofriendly methods of fertilization and biocontrol. Soil microorganisms are the most diverse assemblages of the biosphere and are of great importance for biotechnological applications. The PGPR improve plant growth by carrying out biological nitrogen fixation, hydrolyzing insoluble phosphate, by producing iron-chelating siderophores, and transforming nutrients in the rhizosphere to increase their bioavailability (Mantelin and Touraine, 2004). In addition, they stimulate the plant hormones by producing or metabolizing chemical signaling compounds that directly impact plant growth and function (Patten and Glick, 2002). Many bacterial species belonging to the genera Achromobacter, Arthrobacter, Azospirillum, Bacillus, Burkholderia, Chryseobacterium, Citrobacter, Enterobacter, Herbaspirillum, Klebsiella, Pantoea, Paenibacillus, Pseudomonas, Rhizobium, and others, have been found in the rhizosphere of gramineous plants (Jha et al., 2009).

A collection of 156 microbial strains from different maize-growing regions in Coimbatore, India, were analyzed for their PGP and biocontrol attributes. Many studies have shown that PGPRs act by increasing the nutrient availability for plants (Glick, 1995). Różycki et al. (1999) reported that the majority of the tested strains (77\%) produced ammonia - a significant intermediate in biological nitrogen fixation. In another study, nearly $50 \%$ of the tested strains produced IAA - a phytohormone documented to increaseroot and shoot length as well as enable plants to absorb more nutrients from the soil (Carrillo et al., 2002). Iron is an important prerequisite for all forms of life. But mostly, it is oxidized to $\mathrm{Fe}^{3+}$, thus forming insoluble compounds that become unavailable to microorganisms. Under such circumstances, microorganisms produce low-molecular-weight iron chelators that are called siderophores (Miethke and Marahiel, 2007; Machuca et al., 2007). In our study, 35 strains produced siderophores, indicating their potential role as PGPRs, through depriving plant pathogens of iron and increasing crop yield (O'Sullivan and O'Gara, 1992). We assessed the ability of the strains to hydrolyze phosphates by using a modified Pikovskaya agar with bromophenol blue. The strains produced distinct yellow zones upon hydrolysis of the phosphate, which is not detectable on conventional Pikovskaya's agar. Phosphorous, after nitrogen,is an essential nutrient for plants, but it is predominantly present in insoluble or precipitated forms that cannot be assimilated by the plants (Anand et al., 2016). Of the 156 tested strains, 58 were able to hydrolyze phosphates, thereby indicating their ability to be used as biofertilizers. Many microorganisms have beenreported to produce different lytic enzymes (Huang and Chen, 2004; Gupta et al., 2006). These strains produce mucolytic enzymes such as cellulases and pectinases, which bring about disruption of the components of the fungal cell walls. Ontesting microbial strains, $28 \%$ showed an antagonistic potential to the maize pathogen Fusarium moniliforme under in vitro conditions. The in vitro antifungal activity can be documented by the ability to synthesize different antimicrobial compounds that cause cytolysis, leakage of potassium ions, disruption of the structural integrity of membranes, inhibition of mycelial growth, inhibition of spore germination, and protein biosynthesis (Quan et al., 2010; Yuan et al., 2012).

The results of sequencing and phylogenetic analysis revealed that the majority of isolates belonged to the phyla Firmicutes (Bacillus), followed by Gamma proteobacteria (Pseudomonas, Acinetobacter). Bacteria belonging to the two phyla were found to be associated with many crops such as maize, cotton (Gossypium spp.), or carrots (Daucuscarota) (Surette et al., 2003). In studies involving analyses of the diversity of the bacterial community of maize, Mclnroy and Kloepper (1994) reported that the most commonly isolated genera belonged to the Gammaproteobacteria and Betaproteobacteria divisions. Additionally, Vargas et al. (2009) reported that the $B a$ cillus genus was the most abundant group among the 
Table 2. Identification of the rhizosphere bacterial isolates with their closely related species

by using partial sequencing of the 16s rRNA gene and Genbank accession details

\begin{tabular}{|c|c|c|c|c|}
\hline $\begin{array}{c}\text { Slices } \\
\text { no. }\end{array}$ & $\begin{array}{l}\text { GenBank } \\
\text { accession no. }\end{array}$ & Genus identity & $\begin{array}{l}\text { Similarity } \\
\text { index [\%] }\end{array}$ & Cultural characteristics \\
\hline 1 & KM657433 & Bacillus spp. & 97 & whitish to cream-colored colonies of Gram-positive endospore-forming rods \\
\hline 2 & KT735204 & Bacillus pseudomycoides & 99 & $\begin{array}{l}\text { whitish to cream-colored opaque, usually rhizoid colonies of Gram-positive endospore-forming rods occurring singly or } \\
\text { in short chains }\end{array}$ \\
\hline 3 & KT735205 & Bacillus nematocida & 97 & cream-colored, opaque, smooth, jagged colonies of Gram-positive endospore-forming rods occurring singly or in short chains \\
\hline 4 & KT735206 & Bacillus spp. & 99 & whitish to cream-colored colonies Gram-positive endospore-forming rods \\
\hline 5 & KT735207 & Bacillus thuringiensis & 98 & $\begin{array}{l}\text { whitish to cream-colored, large, circular or irregular colonies of Gram-positive endospore-forming rods with a parasporal } \\
\text { crystal }\end{array}$ \\
\hline 6 & KT735208 & Bacillu ssubtilis & 99 & dry, flat, irregular colonies with lobate margins comprising Gram-positive endospore-forming rods \\
\hline 7 & KM677193 & Klebsiella pneumoniae & 97 & glistening, moist colonies of Gram-negative, straight,encapsulated rods \\
\hline 8 & KM677194 & Acinetobacter pitti & 98 & circular, convex, smooth, slightly opaque colonies of Gram-negative non sporulating rods occurring in pairs or chains \\
\hline 9 & KT735220 & Pseudomonas aeruginosa & 99 & $\begin{array}{l}\text { mucoid colonies with umbonate elevation producing a green diffusible pigment and a distinctive fruity odor and made up } \\
\text { of Gram-negative motile rods }\end{array}$ \\
\hline 10 & KT735210 & Pseudomonas putida & 99 & colonies produce a yellowish to brownish green fluorescent pigment from Gram-negative motile rods \\
\hline 11 & KT735211 & Pseudomonas spp. & 99 & $\begin{array}{l}\text { mucoid colonies with umbonate elevation producing a green diffusible pigment and a distinctive fruity odor and made up } \\
\text { of Gram-negative motile rods }\end{array}$ \\
\hline 12 & KT735221 & Pseudomonas aeruginosa & 98 & $\begin{array}{l}\text { mucoid colonies with umbonate elevation producing a green diffusible pigment and a distinctive fruity odor and made up } \\
\text { of Gram-negative motile rods }\end{array}$ \\
\hline 13 & KT735222 & Pseudomonas spp. & 98 & $\begin{array}{l}\text { mucoid colonies with umbonate elevation producing a green diffusible pigment and a distinctive fruity odor and made up } \\
\text { of Gram-negative motile rods }\end{array}$ \\
\hline 14 & KT735213 & Bacillus firmus & 96 & creamy-yellow colonies with margins entire to finely rhizoidal colonies of Gram-positive endospore-forming rods \\
\hline 15 & KT735214 & Bacillus subtilis & 99 & dry, flat, irregular colonies with lobate margins and made up of Gram-positive endospore-forming rods \\
\hline 16 & KT735215 & Bacillus cereus & 99 & $\begin{array}{l}\text { large, irregular, opaque colonies with a waxy aspect and made up of Gram-positive endospore-forming rods that occur } \\
\text { in chains }\end{array}$ \\
\hline 17 & KP462863 & Bacillus spp. & 99 & whitish to cream-colored colonies of Gram-positive endospore-forming rods \\
\hline 18 & KT735216 & Bacillus cereus & 99 & large, irregular, opaque colonies with a waxy aspect comprising Gram-positive endospore-forming rods that occur in chains \\
\hline 19 & KT735212 & Fictibaciilus spp. & 99 & whitish to cream-colored colonies of Gram-positive endospore-forming rods \\
\hline 20 & KP462864 & Bacillus spp. & 99 & whitish to cream-colored colonies of Gram-positive endospore-forming rods \\
\hline 21 & KP462865 & Bacillus oceanisediminis & 99 & $\begin{array}{l}\text { creamy white, smooth, round colonies with irregular edges and made up of Gram-positive round-ended rods that occur } \\
\text { singly or in pairs }\end{array}$ \\
\hline 22 & KP462866 & Bacillus firmus & 99 & creamy-yellow colonies with margins entire to finely rhizoidal colonies of Gram-positive endospore-forming rods \\
\hline 23 & KP462867 & Bacillus endophyticus & 99 & slimy or rough, usually white or pink colonies of Gram-positive endospore-forming rods \\
\hline
\end{tabular}




\begin{tabular}{|c|c|c|c|c|}
\hline 24 & KT735217 & Bacillus flexus & 95 & opaque and smooth colonies of Gram-stain variable endospore-forming rods \\
\hline 25 & KT735224 & Bacillus licheniformis & 99 & $\begin{array}{l}\text { whitish, round to irregular colonies with undulate margins and made up of Gram-positive, slightly curved endospore-forming } \\
\text { rods }\end{array}$ \\
\hline 26 & KP462868 & Bacillus spp. & 99 & whitish to cream-colored colonies of Gram-positive endospore-forming rods \\
\hline 27 & KT735218 & Bacillus spp. & 97 & whitish to cream-colored colonies of Gram-positive endospore-forming rods \\
\hline 28 & KP462869 & Bacillus anthracis & 99 & large, opaque, non-pigmented colonies of Gram-positive endospore-forming rods \\
\hline 29 & KP462870 & Bacillus cereus & 99 & large, irregular, opaque colonies with a waxy aspect comprising Gram-positive endospore-forming rods that occurin chains \\
\hline 30 & KT735230 & Bacillus pumilis & 95 & wrinkled, irregular, opaque, non-pigmented colonies of endospore-forming rods \\
\hline 31 & KT735231 & Bacillus atrophaeus & 99 & circular, smooth, opaque colonies of Gram-positive endospore-forming rods \\
\hline 32 & KT735232 & Bacillus spp. & 99 & whitish to cream-colored colonies of Gram-positive endospore-forming rods \\
\hline 33 & KT735233 & Bacillus spp. & 96 & whitish to cream-colored colonies of Gram-positive endospore-forming rods \\
\hline 34 & KT735234 & Bacillus cereus & 99 & $\begin{array}{l}\text { large, irregular, opaque colonies with a waxy aspect and made up of Gram-positive endospore-forming rods that occur } \\
\text { in chains }\end{array}$ \\
\hline 35 & KP462871 & Pseudomonas indoloxydans & 99 & mucoid colonies with a slight elevation with pigmentation comprising Gram-negative polarly flagellated rods \\
\hline 36 & KP462872 & Pseudomonas spp. & 98 & $\begin{array}{l}\text { mucoid colonies with umbonate elevation that produce a green diffusible pigment and a distinctive fruity odor composed } \\
\text { of Gram-negative motile rods }\end{array}$ \\
\hline 37 & KP462873 & Pseudomonas indoloxydans & 99 & mucoid colonies with a slight elevation with pigmentation and made up of Gram-negative polarly flagellated rods \\
\hline 38 & KT735219 & Pseudomonas spp. & 99 & $\begin{array}{l}\text { mucoid colonies with umbonate elevation that produce a green diffusible pigment and a distinctive fruity odor and made } \\
\text { up of Gram-negative motile rods }\end{array}$ \\
\hline 39 & KP462874 & Pseudomonas indoloxydans & 99 & mucoid colonies with a slight elevation and pigmentation comprising Gram-negative polarly flagellated rods \\
\hline 40 & KT735225 & Bacillus endophyticus & 99 & slimy or rough, usually white or pink colonies of Gram-positive endospore-forming rods \\
\hline 41 & KT735226 & Bacillus sonorensis & 97 & yellowish cream, with mounds and lobes of amorphous slimy colonies of Gram-positive endospore-forming rods \\
\hline 42 & KT735227 & Bacillus cereus & 99 & large, irregular, opaque colonies with a waxy aspect made up of Gram-positive endospore-forming rods that occur in chains \\
\hline 43 & KT735228 & Bacillus subtilis & 99 & dry, flat, irregular colonies with lobate margins comprising Gram-positive endospore-forming rods \\
\hline 44 & KP462875 & Leucobactertardus & 99 & $\begin{array}{l}\text { lemon-yellow colonies with smooth regular margins comprising Gram-positive asporogenous rods that occur singly or } \\
\text { in clusters }\end{array}$ \\
\hline 45 & KP462876 & Pseudomonas indoloxydans & 99 & mucoid colonies with a slight elevation with pigmentation and made up of Gram-negative polarly flagellated rods \\
\hline 46 & KT735229 & Bacillus amyloliquefaciens & 95 & cream, dull, raised rhizoid colonies of Gram-positive endospore-forming rods in chains \\
\hline 47 & KT735235 & Bacillus atrophaeus & 97 & circular, smooth, opaque colonies of Gram-positive endospore-forming rods \\
\hline 48 & KT735236 & Bacillus spp. & 96 & whitish to cream-colored colonies of Gram-positive endospore-forming rods \\
\hline
\end{tabular}


PGPRs isolated from rice. Similarly, in 2009, Upadhyay et al. documented that the Bacillus genus was dominant in the root-adhering soil of wheat under saline conditions. The next dominant genera in soil were Pseudomonas, which have wide spread application as PGP and biocontrol agents because of their multifaceted mechanism of action (Walsh et al., 2001). The genera Pantoea, Acinetobacter, Klebsiella, and Pseudomonas have been reported to be associated with several poaceous plants, including sweet sorghum (Sorghum bicolor), sugarcane (Saccharum officinarum), maize (Zea mays), rice (Oryza sativa), and others (Mareque et al., 2015), and are indicated as good PGPRs.

Biofertilization and biocontrol are the major applications of PGPRs in maize (Perez et al., 2014). This study focused on heterogenous groups of microorganisms from the rhizosphere of maize. These strains live in and around the root systems and stimulate plant growth and/or reduce plant disease rates. Among the rhizospheric microorganisms, Bacillus and Pseudomonas are the genera that are most predominantly studied in research due to their wide spectrum of action as PGP and biocontrol agents (Nautlyal et al., 2002). The toxigenic fungus Fusarium is one of the major genera associated with pathogenicity in maize (Perez et al., 2014). Some PGPRs, such as Bacillus amyloliquefaciens, were able to confer protection to maize against Fusarium verticillioides when applied in the form of seed coatings (Pereira et al., 2011). Strains of Bacillus cepacia have been associated with biocontrol characteristics against Fusarium spp., and also stimulate the growth of maize under ironpoor conditions via siderophore production (Bevivino et al., 1998). All strains used in this study possessed at least one positive feature that indicated they were PGPRs. With respect to the production of ammonia, our results are similar to those of the study carried out by Różycki et al. (1999), who showed the presence of nitrogenase activity insome of the diazotrophic isolates belonging to the genera Pseudomonas and Bacillus. In terms of IAA production, Islam et al. (2016) reported that rhizosphere isolates from cucumber showed a varied production of IAA, with differing concentrations of L-tryptophan. Bacterial genera belonging to Pseudomonas, Bacillus, Rhizobium, and Mesorhizobium have been reported to produce high levels of IAA (Verma et al., 2013). Several reports have proved that siderophore-producing bacteria significantly increase the plant uptake of metals such as $\mathrm{Fe}, \mathrm{Zn}$, and $\mathrm{Cu}$ (Gururani et al., 2012). Kumar et al. (2012) reported that many different strains of Bacillus and Pseudomonas have good potential as biocontrol agents due to their increased antifungal activity, and this is similar to the results obtained in the present study. The application of these multitrait targetspecific PGPs may be facilitate their use as bioinoculants in agriculture after suitable trials in a greenhouse and under field conditions.

Extensive greenhouse studies under pot and field trials will facilitate the identification of potent strains that could be commercialized and used as biofertilizers or biocontrol agents. These native potential strains in different formulations with an increased spectrum of activity will enable faster commercialization of this technology.

\section{Conclusion}

There is a rich bacterial diversity in the rhizosphere of maize plants from different maize-growing regions of Coimbatore, Tamil Nadu, India. Knowledge of the diversity of these bacterial agents is not only required to understand their ecology but also for their application insustainable agricultural practices. Therefore, the best strains were selected on the basis of their in vitro $\mathrm{PGP}$ traits such as phosphate solubilization and production ofIAA, siderophores and mucolytic enzymes; these were subsequently identified using molecular approaches such as $16 \mathrm{~S}$ rRNA sequencing. The majority of the strains possessed at least one positive feature that characterized them as good PGP candidates. Most strains belonged to the genera Bacillus and Pseudomonas, followed by Acinetobacter, Klebsiella, Lecucobacter, and Pantoea that are not widely harnessed as PGPR agents. These strains do not work independently of each other but act synergistically and are thus able to increase crop yield. These potential PGP strains can be efficient bioinoculants in sustainable agriculture. These strains with innate biofertilizing and biocontrol potential will show an enhanced spectrum of activity when compared to strains introduced from other ecosystems.

\section{Acknowledgments}

The authors acknowledge the financial assistance provided by the Department of Biotechnology, Government of India, New Delhi, for this research project (grant no. BT/PR4683/AGR/ 21/353/2012). 


\section{References}

Altschul S., Stephen F., Madden T., Schaffer A., Zhang J., Zhang Z., Miller W., Lipman D., (1997) Gapped BLAST and PSIBLAST: a new generation of protein database search programs. Nucl. Acids Res. 25: 3389-3402.

Anand K., Kumari B., Mallick M.A. (2016) Phosphate solubilizing microbes: an effective and alternative approach as bio-fertilizers. Int. J. Pharm. Sci. 8(2): 37-40.

Bashan Y., Levanomy H. (1990) Current status of Azospirillum inoculation technology: Azospirillum as a challenge for technology. Can. J. Microbiol. 36(9): 591-608.

Bevivino A., Sarrocco S., Dalmastri S., Tabacchioni S., Cantale C. Chiarini L. (1998) Characterization of a free-living maize rhizosphere population of Burkholderiacepacia: effect of seed treatment on disease suppression and growth promotion of maize. FEMS. Microbiol. Ecol. 27: 225-237.

Bric J.M., Bostock R.M., Silverstone S.E. (1991) Rapid in situ assay for indoleacetic acid production by bacteria immobilized on a nitrocellulose membrane. Appl. Environ. Microbiol. 57(2): 535-538.

Cappuccino J.G., Sherman N. (1992) Microbiology: a laboratory manual. $3^{\text {th }}$ Ed., Benjamin/Cummings Pub. Co., New York: $125-179$.

Carrillo A.E., Li C.Y., Bashan Y. (2002) Increased acidification in the rhizosphere of cactus seedlings induced by Azospirillumbrasilense. Naturwissenschaft. 89(9): 428-432.

Cattelan A.J., Hartel P.G., Furhmann F.F. (1999) Screening for plant growth promoting rhizobacteria to promote early soybean growth. Soil. Sci. Soc. Am. J. 63: 1670-1680.

Das K., Doley R., Mukherjee A.K. (2004) Purification and characterization of a thermostable alkaliphilic extracellular alpha-amylase from Bacillus subtilis DM-03 a strain isolated from the traditional fermented food of India. Biotechnol. Appl. Biochem. 40(3): 291-298.

European Environment Agency (2015) European environment state and outlook assessment of global megatrends. ISBN 978-92-9213-534-8.

Glick B.R. (2014) Bacteria with ACC deaminase can promote plant growth and help to feed the world. Microbiol. Res. 169(1): 30-39.

Glick B.R. (1995) The enhancement of plant growth by free living bacteria. Can. J. Microbiol. 41: 109-114.

Gupta C.P., Kumar B., Dubey R.C., Maheshwari D.K. (2006) Chitinase mediated destructive antagonistic potential of Pseudomonas aeruginosa GRC1 against Sclerotinia sclerotiorum causing charcoal rot of peanut. BioControl. 51: 821-835.

Gupta R., Singal R., Shankar A., Kuhad R.C., Saxena R.K. (1994) A modified plate assay for screening phosphate solubilizing microorganisms. J. Gen. Appl. Microbiol. 40(3): 255-260.

Gururani M.A., Venkatesh J., Upadhyaya C.P., Nookaraju A., Pandey S.K., Park S.W. (2012) Plant disease resistance genes: current status and future directions. Physiol. Mol. Plant Pathol. 78: 51-65.
Hsu S.C., Lockwood J.L. (1975) Powdered chitin agar as a selective medium for enumeration of actinomycetes in water and soil. Appl. Microbiol. 29(3): 422-426.

Huang C.J., Chen C.Y. (2004) Gene cloning and biochemical characterization of chitinase CH from Bacillus cereus 28-9. Ann. Microbiol. 53(3): 289-297.

Islam S., Akanda A.M., Prova A., Islam M.T., Hossain, M.M. (2016) Isolation and identification of plant growth promoting rhizobacteria from cucumber rhizosphere and their effect on plant growth promotion and disease suppression. Front Microbiol. 6: 1360.

Jha B.K., Pragash M.G., Cletus J., Raman G., Sakthivel N. (2009) Simultaneous phosphate solubilization potential and antifungal activity of new fluorescent pseudomonad strains Pseudomonas aeruginosa $P$. plecoglossicida and P. mosselii. World J. Microbial. Biotechnol. 25: 573-581.

Joshi K.K., Dubey R.C., Bajpai V.K. (2006) Effect of chemical fertilizer-adaptive variants, Pseudomonas aeruginosa GRC2 and Azotobacterchroococcum AC1, on Macrophominaphaseolina causing charcoal rot of Brassica juncea. Korean J. Environ. Agric. 25(3): 228-235.

Kasana R.C., Salwan R., Dhar H., Dutt S., Gulati A. (2008) A rapid and easy method for the detection of microbial cellulases on agar plates using Gram's iodine. Curr. Microbiol. 57(5): 503-507.

Kumar A., Sharma R. (2012) Production of alkaline pectinase by bacteria (Cocci sps.) isolated from decomposing fruit materials. J. Phytol. 4(1): 1-5.

Ladeiro B. (2012) Saline agriculture in the $21^{\text {st }}$ century: using salt contaminated resources to cope food requirements. J. Bot. 1-7. DOI: 10.1155/2012/310705.

Lahlali R., Bajii M., Jijakli M.H. (2007) Isolation and evaluation of bacteria and fungi as biological control agents against Rhizoctoniasolani. Commun. Agric. Appl. Biol. Sci. 72(4): 973-982.

Machuca A., Pereira G., Aguiar A., Milagres A.M. (2007) Metal-chelating compounds producedby ectomycorrhizal fungi collected from pine plantations. Lett. Appl. Microbiol. 44: 7-12.

Mantelin S., Touraine B. (2004) Plant growth-promoting bacteria and nitrate availability: impacts on root development and nitrate uptake. J. Exp. Bot. 55: 27-34.

Mareque C., Taulé C., Beracochea M., Battistoni F. (2015) Isolation characterization and plant growth promotion effects of putative bacterial endophytes associated with sweet sorghum (Sorghum bicolor (L) Moench). Ann. Microbiol. 65: 1057-1067.

McInroy J.A., Kloepper J. (1994) Novel bacterial taxa inhabiting internal tissues of sweet corn and cotton. [in:] Improving plant productivity with rhizosphere bacteria. Eds. Ryder M.H., Stephens P.M., Bowen G.D. CSIRO. Melbourne.

Mehnaz S., Kowalik T., Reynolds B., Lazarovitz G. (2010) Growth promoting effects of corn (Zea mays) bacterial strains under greenhouse and field conditions. Soil Biol. Biochem. 42: 1848-1856. 
Miethke M., Marahiel M.A. (2007) Siderophore-based iron acquisition and pathogen control. Microbiol. Mol. Biol. Rev. 71: 413-451.

Nautlyal C.S., Johri J.K., Singh H.B. (2002) Survival of the rhizosphere-competent biocontrol strain Pseudomonas fluorescensNBRI2650 in the soil and phytosphere. Can. J. Microbiol. 48: 588-601.

O'Sullivan D.J., O'Gara F. (1992) Traits of fluorescent Pseudomonas spp. involved in suppression of plant root pathogens. Microbiol. Rev. 56: 662-676.

Patten C.L., Glick B.R. (2002) Role of Pseudomonas putida indoleacetic acid in development of the host plant root system. App. Environ. Microbiol. 68: 3795-3801.

Peiffer J.A., Ley R.E. (2013) Exploring the maize rhizosphere microbiome in the field: a glimpse into a highly complex system. Commun. Integr. Biol. 6(5): e25177.

Pereira P., Ibáñez S.G., Agostini E., Etcheverry M. (2011) Effects of maize inoculation with Fusarium verticillioides and with two bacterial biocontrol agents on seedlings growth and antioxidative enzymatic activities. Appl. Soil Ecol. 51: 52-59.

Pérez-Montaño F., Alías-Villegas C., Bellogín R.A., Del Cerro P., Espuny M.R., Jiménez-Guerrero, I., López-Baena F.J., Ollero F.J., Cubo T. (2014) Plant growth promotion in cereal and leguminous agricultural important plants: from microorganism capacities to crop production. Microbiol. Res. 169(5-6): 325-336.

Quan C.S., Wang X., Fan S.D. (2010) Antifungal compounds of plant growth promoting rhi-zobacteria and its action mode. [in:] Plant growth and health promoting bacteria. Ed. D.K. Maheshwari. Berlin-Heidelberg: Springer Verlag: 117-156.

Różycki H., Dahm H., Strzelczyk E., Li C.Y. (1999) Diazotrophic bacteria in root-free soil and in the root zone of pine (Pinussylvestris L.) and oak (Quercusrobur L.). Appl. Soil Ecol. 12(3): 239-250.

Saitou N., Nei M. (1987) The neighbour-joining method: a new method for reconstructing phylogenetic trees. Mol. Biol. Evol. 4(4): 406-425.

Sambrook J., Fritsch E.F., Maniatis T. (1989) Molecular cloning: a laboratory manual. $2^{\text {nd }}$ Ed. Cold Spring Harbor Laboratory Press.

Schwyn B., Neilands J.B. (1987) Universal chemical assay for the detection and determination of siderophores. Anal. Biochem. 160(1): 47-56.

Sivasakthi S., Usharani G., Saranraj P. (2014) Biocontrol potentiality of plant growth promoting bacteria (PGPR)Pseudomonas fluorescens and Bacillus subtilis: a review. Afr. J. Agric. Res. 9(16): 1265-1277.
Surette M.A., Sturz A.V., Lada R.R., Nowak J. (2003) Bacterial endophytes in processing carrots (Daucuscarota L. var. sativus): their localization population density biodiversity and their effects on plant growth. Plant Soil. 253: 381-390.

Swarnalakshmi K., Prasanna R., Kumar A., Pattnaik S., Chakravarty K., Shivay Y.S., Singh R., Saxena A.K. (2013) Evaluating the influence of novel cyanobacterial biofilmed biofertilizers on soil fertility and plant nutrition in wheat. Eur. J. Soil Biol. 55: 107-116.

Tamura K., Peterson D., Peterson N., Stecher G., Nei M., Kumar S. (2011) MEGA 5: molecular evolutionary genetics analysis using maximum likelihood evolutionary distance and maximum parsimony method. Mol. Biol. Evol. 28(10): 2731-2739.

Upadhyay S.K., Singh D.P., Saikia R. (2009) Genetic diversity of plant growth promoting rhizobacteria isolated from rhizospheric soil of wheat under saline condition. Curr. Microbiol. 59(5): 489-496.

Vargas L.K., Lisboa B.B., Schlindwein G., Granada C.E., Giongo A., Beneduzi A., Passaglia L.M.P. (2009) Occurrence of plant growth-promoting traits in clover-nodulating rhizobia strains isolated from different soils in Rio Grande do Sul state. Rev. Brasil. Ciên Solo 33(5): 1227-1235.

Verma J.P., Yadav J., Tiwari K.N., Kumar A. (2013) Effect of indigenous Mesorhizobium spp. and plant growth promoting rhizobacteria on yields and nutrients uptake of chickpea (Cicer arietinum L.) under sustainable agriculture. Ecol. Eng. 51: 282-286.

Walsh U.F., Morrissey J.P., O'Gara F. (2001) Pseudomonas for biocontrol of phytopathogens: from functional genomics to commercial exploitation. Curr. Opin. Biotechnol. 12(3): 289-295.

Whipps J.M. (2001) Microbial interactions and biocontrol in the rhizosphere. J. Exp. Bot. 52: 487-511.

Wu S.C., Cao Z.H., Li Z.G., Cheung K.C., Wong M.H. (2005) Effects of biofertilizer containing $N$-fixer $P$ and $K$ solubilizers and AM fungi on maize growth: a greenhouse trial. Geoderma. 125: 155-166.

Yuan J., Li B., Zhang N., Waseem R., Shen Q., Huang Q. (2012) Production of bacillomycin- and macrolactin-type antibiotics by Bacillus amyloliquefaciens NJN-6 for suppressing soilborne plant pathogens. J. Agric. Food. Chem. 60: 2976-2981.

Zahid M., Abbasi M.K., Hameed S., Rahim N. (2015) Isolation and identification of indigenous plant growth promoting rhizobacteria from Himalayan region of Kashmir and their effect on improving growth and nutrient contents of maize (Zea mays L.). Front. Microbiol. 6: 207. 